\title{
Significations du basket-ball
}

Entre constantes corporelles et variabilité socio-historique

What Does Basketball Mean? Halfway Between Physical Constants and Sociohistorical Variants

\section{Éric Claverie}

\section{(2) OpenEdition Journals}

Édition électronique

URL : https://journals.openedition.org/tc/8412

DOI : $10.4000 /$ tc. 8412

ISSN : 1952-420X

\section{Éditeur}

Éditions de l'EHESS

\section{Édition imprimée}

Date de publication : 1 décembre 2014

Pagination : 208-229

ISBN : 978-2-7351-2346-9

ISSN : 0248-6016

\section{Référence électronique}

Éric Claverie, «Significations du basket-ball », Techniques \& Culture [En ligne], 62 | 2014, mis en ligne le 01 décembre 2017, consulté le 30 septembre 2022. URL : http://journals.openedition.org/tc/8412 ; DOI : https://doi.org/10.4000/tc.8412 

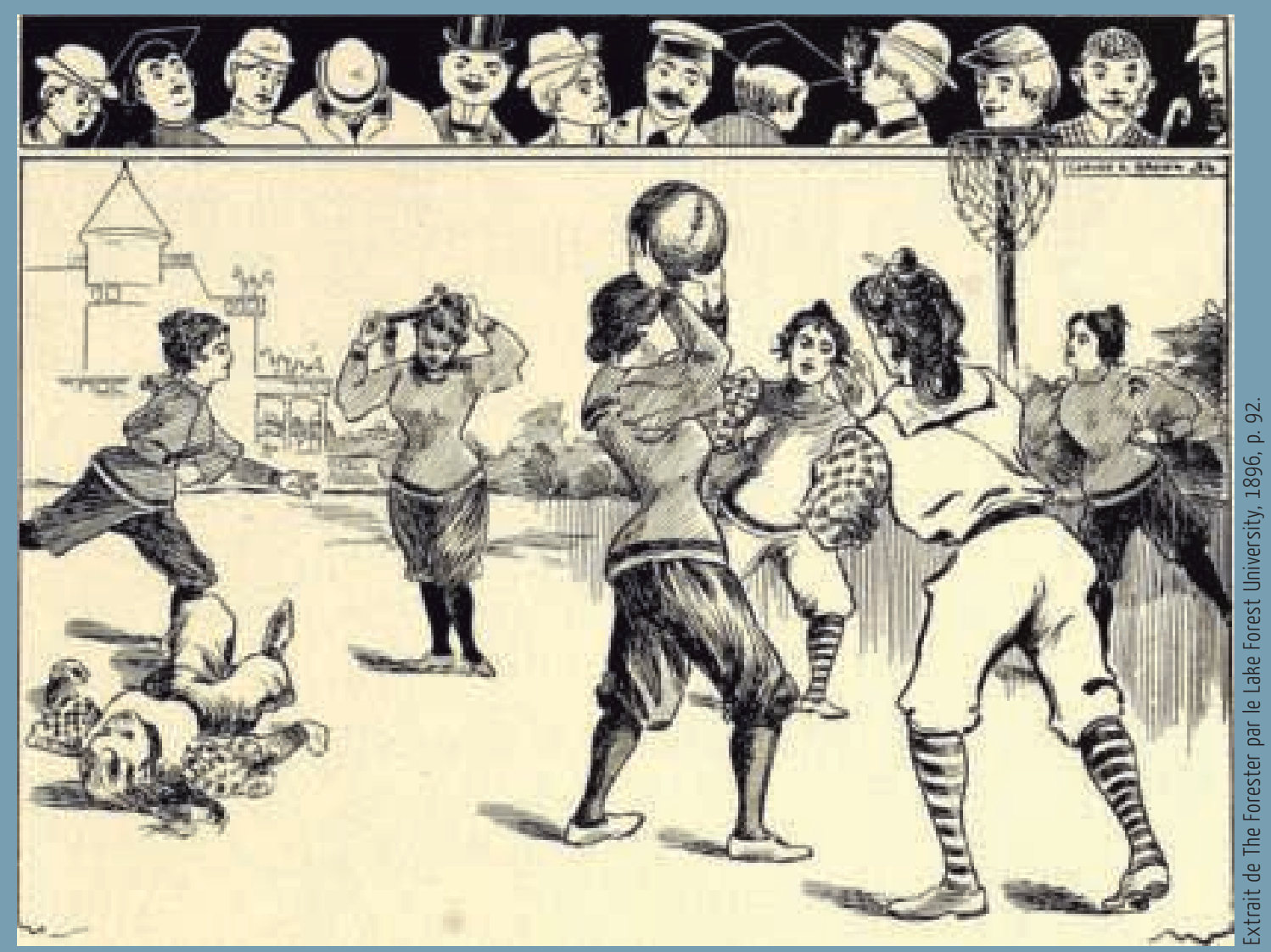


\section{SIGNIFICATIONS DU BASKET-BALL}

\section{Entre constantes corporelles \\ et variabilité socio-historique}

En 1934, lorsque l'international français de basket-ball Onimus pose muscles saillants en illustration d'un article intitulé « Le basket-ball est-il un sport ? ${ }^{1} »$, il entend attirer le regard du côté de sa plastique «mâle », et ainsi dissiper de persistantes représentations en France: «jeu pour vieux colonels », «jeu de petites filles nécessitant peu d'efforts ». Étonnant renversement vis-à-vis d'une création ludique anglo-saxonne pourtant marquée dès sa naissance du sceau de la masculinité virile. Deux décennies plus tard, Robert Busnel ${ }^{2}$ figure légendaire du basket-ball français, combat à sa manière la dimension récréative de l'activité. Il déclare ainsi : «Inventé dans une grande école, pratiqué dans les universités, le basket-ball fut dès l'origine et, est resté, un sport intellectuel. C'est là son caractère essentiel » (Busnel 1953). D'un côté, l'image d'une pratique modérée et trop féminine au goût de ses détracteurs; d'un autre côté, celle d'un sport cérébral injustement accusé de futilité. Voici, parmi d'autres, quelques-unes des significations auxquelles renvoie curieusement le basket-ball dans la première moitié du xx siècle français. D'où proviennent ces représentations? Sont-elles héritées de la matrice américaine originelle ou au contraire de la prégnance de la culture d'accueil? Plus généralement, quelle part accorder à la structure formelle initiale de ce jeu au regard de la perméabilité aux époques et espaces traversés?

Notre projet emprunte à l'anthropologie historique ${ }^{3}$ des sports et s'inscrit dans la veine de productions récentes (Robène \& Léziart 2006; Darbon 2008, 2014). Il désire d'une part extraire les structures et éléments pérennes des rationalités corporelles de ce jeu, et par voie de conséquence, en comprendre leurs significations. En 
effet, il y aurait les gestes, et au-delà des aspects de surface, la raison des gestes qui détermine «leur efficacité symbolique, [...] [leurs] conditions de possibilité et de légitimité » (Schmitt 1990). En ce sens, l'entreprise nourrit un champ de recherche insuffisamment fécond dans le domaine des sciences du sport et entend mettre au jour «les formes corporelles du savoir et les dynamiques de transformations des techniques s'incarnant dans la production des gestes intégrant le triple niveau historiquement situé de la réalisation, de la fonctionnalité et de la symbolique» (Robène \& Léziart 2006). En s'inspirant de travaux pionniers (Vigarello 1988), le projet est donc également historique : il ambitionne d'abord de resituer ces usages du corps sportif dans le contexte particulier de leur création. Puis au-delà, explorant la diachronie, il tente aussi de faire émerger la variabilité spatiale et temporelle de ces mêmes rationalités gestuelles, diversement retravaillées selon les environnements socioculturels auxquels elles s'acclimatent. En définitive, notre démarche se donne pour objectif d'« apprécier l'impact de la "variation" historique sur la "variante" structurelle» (Schmitt 2008) des gestes et usages pratiques du basket-ball.

Ainsi après d'autres, ayant exploré le registre de l'anthropologie des pratiques sportives ${ }^{4}$, soucieux d'en dévoiler «les caractéristiques intrinsèques, c'est-à-dire les relations entre règles du jeu, propriétés formelles et cultures sportives» (Darbon 2010), nous cherchons d'abord à extraire les racines de l'œuvre ludique du ministre presbytérien James Naismith ${ }^{5}$ afin d'en comprendre le sens originel. Dans ce cadre, l'étude du corpus réglementaire initial se révèle prioritaire pour faire émerger la « logique interne ${ }^{6} »$ du basket-ball et en apprécier les conséquences, tant celle-ci «réalise un façonnage corporel [et] impose un système de normes que le joueur intériorise et fait passer dans son corps lorsqu'il joue » (Parlebas 1981). Par ailleurs, la compréhension du contexte idéologico-religieux de la fin du XIXe siècle étasunien permet tout autant de saisir en quoi la «logique externe» se marie efficacement à ce premier système de contrainte pour donner au basket-ball sa gestuelle signifiante.

La deuxième partie de l'article étudie la variabilité sociohistorique de cette matrice ludique. Deux exemples d'acclimatation à de nouveaux univers socioculturels sont exposés. Acclimatation à la société française de l'entre-deux-guerres d'abord, qui, persuadée de le façonner à ses normes, incorpore pourtant bon nombre des fondements axiologiques américains. Acclimatation ensuite aux cultures urbaines des sociétés postindustrielles qui lui confèrent une dimension transnationale (Fournier \& Raveneau 2010) et transgressive vis-à-vis de l'académisme sportif. Ces exemples tendent à nuancer l'hypothèse de l'universalité du noyau corporel des origines et à valider celle de l'extrême plasticité des pratiques sportives au contexte environnant. Au final, notre démarche, observant la diffusion internationale d'objets très malléables, rejoint celle de Sébastien Darbon lorsqu'il cherche à percer à jour «le jeu dialectique complexe entre la dimension universelle et la dimension contextuelle des cultures sportives» (Darbon 2010). Quant aux conclusions, en phase avec les avancées récentes (Singaravelou \& Sorez 2010; Fournier \& Raveneau 2010), elles tendent in fine à invalider l'idée selon laquelle les propriétés techniques intrinsèques des disciplines sportives déterminent à elles-seules leurs règles de diffusion. 


\title{
Aux origines d'un jeu sportif: contexte et propriétés formelles
}

\author{
Le corps réglementaire d'un «artefact culturel» \\ ou la réponse rationnelle à un besoin
}

La formule de l'instructeur physique James Naismith est suffisamment connue pour être longuement commentée: "The invention of basketball was not an accident. It was developed to meet a need». Il est aujourd'hui entendu que sa création, à la fin de l'année 1891 dans la School of Christian Workers de Springfield, Massachusetts, fut d'abord une réponse pédagogique à la lassitude des jeunes gens en quête pressante de "plaisir» et de «frisson » issus des sports collectifs naissants. Il constitue bien un «artefact culturel à définir, utiliser, redéfinir» (Guttmann 1978).

La part de rationalité de l'entreprise est notoire. La démarche déductive conduisant des intentions générales aux règles en passant par les principes ludo-moteurs, témoigne de la maturation d'un projet ne devant ni à la tradition, ni au hasard. Quel est alors le noyau fondamental de ce jeu qui en fait son identité motrice et axiologique? Quatre caractéristiques se dégagent sans contestation de ce corpus originel, et de l'analyse qu'en fit plus tardivement son testateur (Naismith 1996).

La première concerne l'habileté gestuelle: «accuracy»(précision), «agility» (agilité), «skill » (habileté) sont les termes retenus par Naismith pour décrire les savoir-faire d'un jeu construit en opposition à la violence du football américain. Adresse, dextérité, manualité experte nourrissent ainsi avec abondance les premiers discours du basket-ball et sa mythologie. Les virtuoses du dribble ou de la passe seront ainsi qualifiés de magiciens, quasi dissimulateurs de leurs intentions, à l'image de Bob Cousy, «le Houdini des parquets» des années 1960, ou encore des «artistes géniaux et mystificateurs ${ }^{7}$ » des Harlem Globetrotters. La motricité du basketteur, avant tout affaire de précision et de délicatesse, s'oppose donc au registre de la force ou de la puissance.

De ce fait, elle est aussi affaire de contrôle de soi. Contrôle millimétré des lancers certes, mais également respect de la double contrainte réglementaire originelle: immobilité en possession du ballon et impératif défensif du no contact face à un adversaire. La maîtrise des projections se double donc d'une capacité d'évitement et d'une savante science de la locomotion. Les compétences motrices s'accompagnent en outre d'une vertu morale: le respect de l'intégrité d'autrui et la contenance de

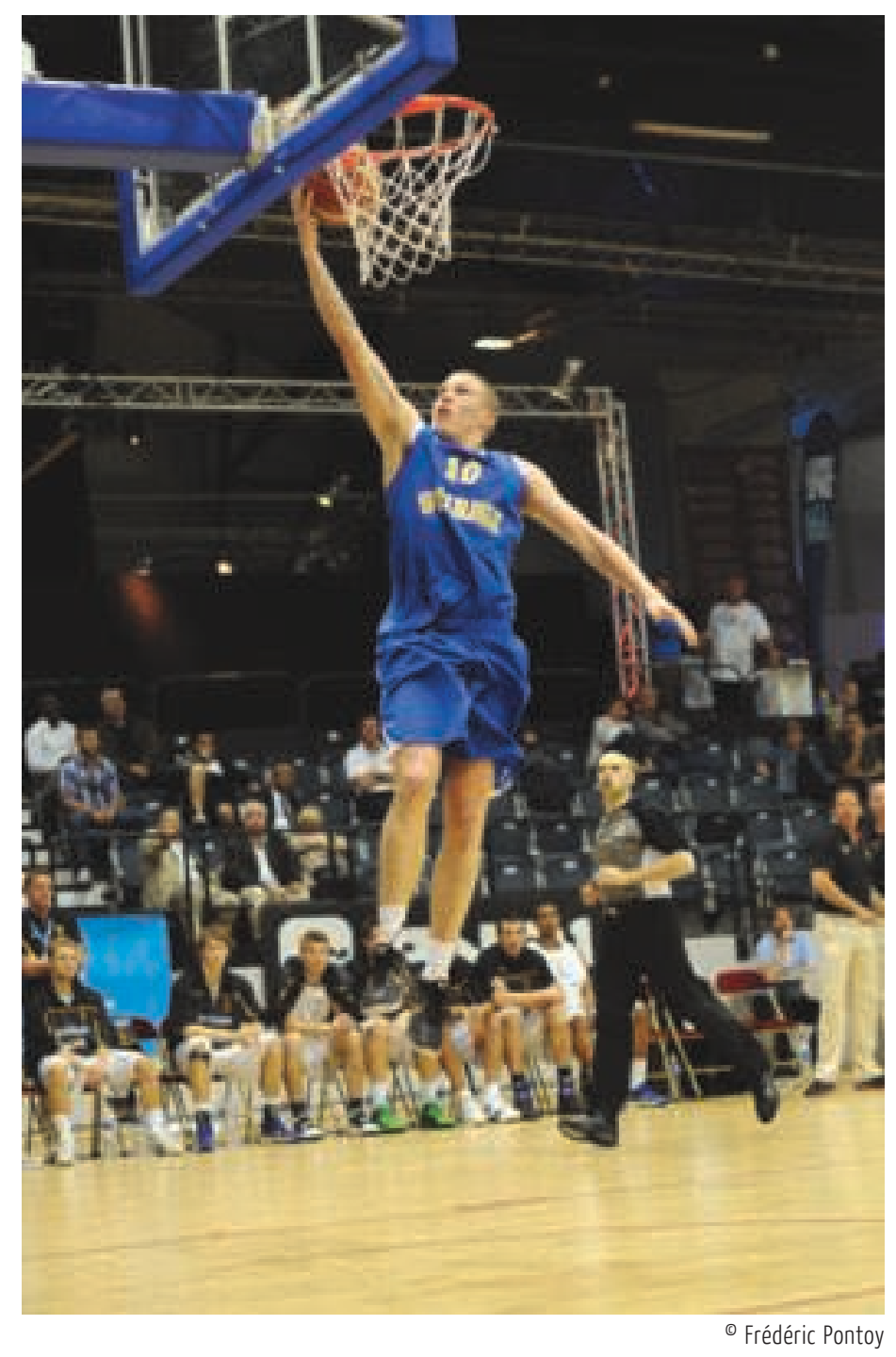


ses propres émotions. En comptabilisant chacun des moindres écarts vis-à-vis du code du non-contact, en imposant au responsable de reconnaître publiquement sa faute, le règlement contient les ingrédients de cette stricte exigence morale.

Les deux autres traits essentiels se tiennent en deçà de ces premières valeurs cardinales. Le premier, traduit par Naismith sous les vocables de «alertness», «speed» ou encore «reflex judgment », est celui de la vitesse qui s'accorde d'ailleurs harmonieusement aux notions d'évitement tout en réfutant celle de la puissance lente et progressive. La célérité est celle des démarrages et des impulsions des joueurs, plus explosives que soutenues et plus localisées qu'étendues, mais aussi celle du jeu susceptible de se déplacer en une fraction temporelle d'une cible à l'autre, de rebondir d'un événement à un autre. Cette valeur qui est aussi celle de la modernité d'une nation dans son essor économique et technologique de la fin du XIx siècle est d'ailleurs fréquemment admise dans la vulgate américaine du jeu comme option tactique première: le «fast-break» (contre-attaque) et le «run and gun» (courir et tirer rapidement). Cette propension à la vélocité recouvre aussi celle de la prise de décision instantanée et discernée, rejoignant ici le contrôle de soi. La vitesse est donc également celle de la fulgurance de la perception qui rejoint sa sûreté.

L'ultime trait issu du corps réglementaire tient à la richesse stratégique d'un jeu «suffisamment scientifique ${ }^{8}$ » pour lui donner de la longévité et satisfaire les joueurs les plus expérimentés. En proposant dès le début une organisation tactique à neuf postes de jeu, Naismith offre déjà au basket-ball une riche panoplie de rôles possibles. Logiquement, elle conduit rapidement à l'élaboration de schémas planifiés, et à une prévision intellectuelle du déroulement du jeu. Le succès et la présence du basket-ball dans le milieu universitaire, mais également son enseignement sous la férule d'un professeur-entraîneur conduiront finalement à asseoir son statut de sport cérébral.

Ces attributs tissent la trame identitaire originelle du basket-ball. Mûrement choisis pour en faire un support récréatif et éducatif, sélectionnés dans un contexte pédagogique et religieux, ils ne doivent rien au hasard. Peut-être est-ce pour cela qu'ils continuent à s'exprimer avec autant de force: l'adresse des tireurs, imprévisible jusqu'aux ultimes secondes du jeu reste bien le puissant attracteur des foules; de son côté le règlement, qui n’a rien cédé aux exigences du contrôle de soi, continue à réclamer la maîtrise des déplacements même si l'intransigeance du no contact s'est adoucie'. Cette réalité contemporaine milite en faveur de l'hypothèse de la continuité historique de ces propriétés formelles issues d'un système de règles aussi original qu'inédit. Or l'émergence de ce rapport au corps construit par l'esprit humain doit également s'entendre dans un contexte plus général.

\section{Muscular christianity et esprit du capitalisme}

Le projet de Naismith, ou plus exactement de son inspirateur et véritable théoricien du dessein sportif des YMCA (Young Man Christian Association ${ }^{10}$ ), le responsable du Physical Departement de Springfield Luther H. Gulick, n'est pourtant pas qu'éducatif. Il se double d'une éthique religieuse modernisée servant un prosélytisme protestant. En cela, il épouse aussi les valeurs du capitalisme anglo-saxon, faisant des adeptes de ce sport les nouveaux conquérants d'une société américaine en pleine accélération économique et technologique, tout comme les gardiens d'une morale ascétique et rigoureuse.

La puissance du mouvement YMCA américain illustre la présence protestante massive dans le sport moderne dès l'articulation des XIXe et XX $x^{e}$ siècles. Créant de nouveaux 
supports d'exercice (le basket-ball en 1891 puis le volley-ball en 1895), s'appuyant sur des pratiques de provenance anglaise (l'athlétisme revisité par les Public Schools), rénovant et théorisant les gymnastiques traditionnelles (Gulick 1889), les instructeurs physiques protestants s'inscrivent finalement dans la continuité d'une présence depuis longtemps avérée dans le champ des exercices du corps en Europe (Hurtebize 1990). Leur réussite lors des confrontations sportives internationales (Guttmann 1978) conforte la thèse de la compatibilité entre l'«ascétisme séculier » protestant (Weber 1964) et leur appétence pour les exercices du corps.

Pourtant dans l'esprit protestant de cette fin du XIXe, le goût pour l'effort s'entend à l'exclusion d'une banale quête sensorielle. Ainsi: «Le sport était suspect en tant qu'il laissait un cours libre et spontané aux impulsions indomptées». L'exercice du corps se conçoit plutôt au double sens d'une pratique d'autocontrôle de ses instincts immédiats et d'un dispositif éducatif soumis à la raison de son instructeur. Au-delà, son usage participe pleinement de la diffusion de la muscular christiannity dont les YMCA assurent la promotion. Doctrine née dans le champ littéraire anglais au milieu du xixe siècle (Parker $\&$ Watson 2014), elle favorise l'émergence dans les milieux éducatifs d'une figure masculine virile et pieuse, représentative d'une élite conquérante au service d'une puissance

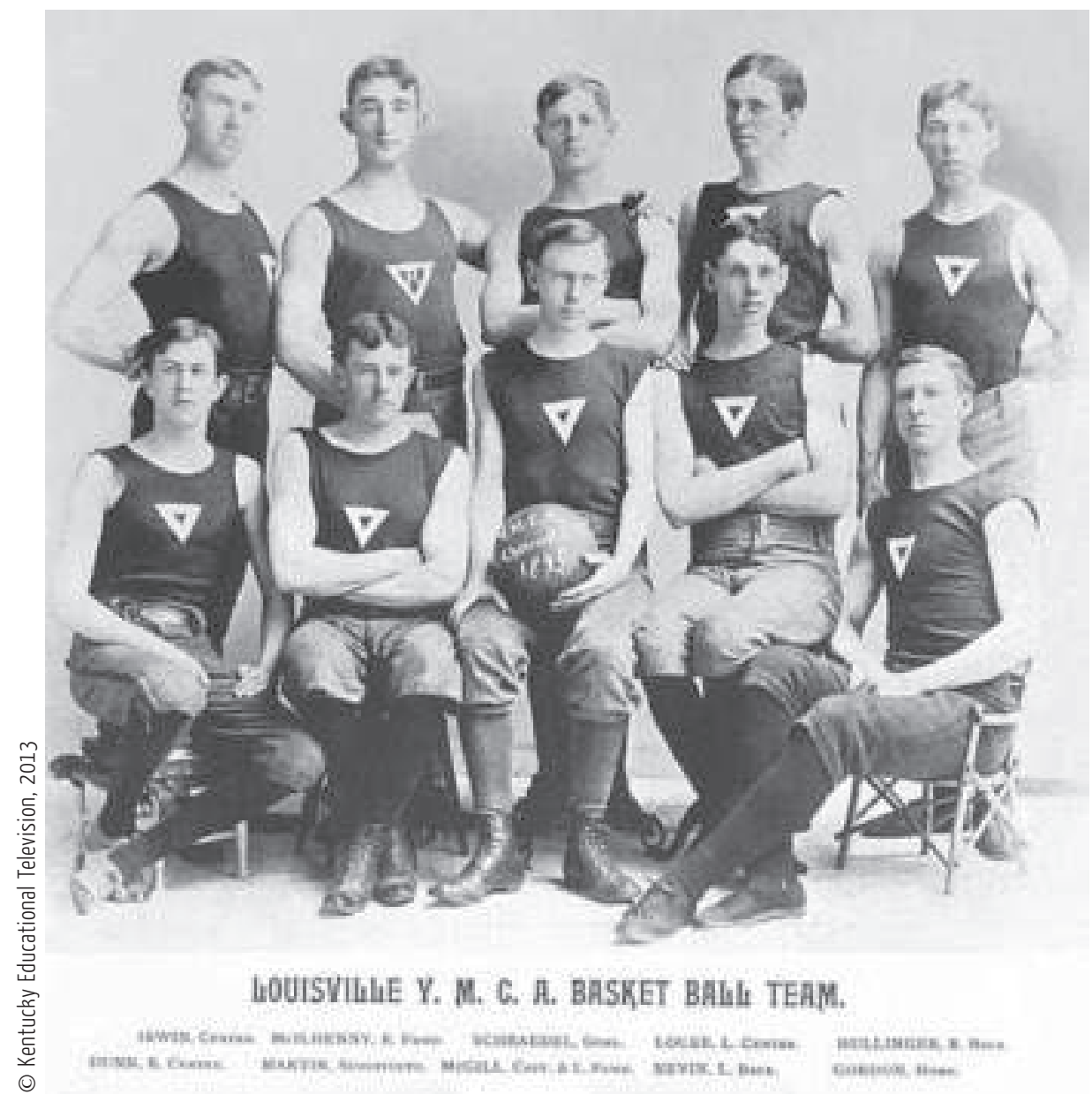

Équipe YMCA de Louisville, 1895 
culturelle et économique. Dès leur origine, les jeux sportifs modernes sont donc conçus comme des leviers importants de la formation du caractère et de la «santé morale des garçons: caractère, retenue, honneur, impartialité, désintéressement ${ }^{11}$.

Sans contredire cet idéal de virilité et d'autocontrôle ${ }^{12}$ (Riess 1991), la version américaine représente également une ressource face à l'angoisse d'une décadence physique et morale américaine provoquée par l'urbanisation, la sédentarité et l'arrivée en masse d'une immigration non protestante. Le mythe de la ville corruptrice et de ses effets délétères sur la moralité de l'individu se tient en surplomb de ces représentations sociales. Le registre corporel du basket-ball, né des principes de Gulick et mis en œuvre par Naismith, privilégiant largement l'autocensure morale et la retenue en même temps que le salut collectif par la figure virile de la masculinité, épouse donc pleinement ce système doctrinal.

Il incarne également avec pertinence les traits du capitalisme anglo-saxon, donnant en exemple les liens depuis longtemps établis par M. Weber. Poursuivant son travail fondateur, S.J. Overmann identifie les facteurs de l'éthique sportive protestante américaine structurée au XIXe siècle: l'ascétisme moral, la rationalisation des actions, le légalisme, le comportement d'accomplissement, l'assimilation sport-travail, l'individualisme, l'esprit de compétition et l'ascension sociale par ce biais (Overmann 2011).

La professionnalisation précoce des sports américains au Xixe siècle, balayant assez rapidement une résistance puritaine et adoptant le modèle efficient de l'entreprise, illustre clairement cette osmose. À l'image de ses deux aînés: le football et le base-ball, le basketball s'engouffre vite dans cette voie, et le délaissement progressif de son contrôle par l'institution mère YMCA, dès la fin de la décennie 1890, ouvre la voie à une marchandisation des compétences des premiers experts. D’autres indices confortent la thèse d'Overmann, parmi lesquels la rationalisation des actions semble être le plus perceptible: mise en chiffre de la performance au travers de l'outil statistique, «méthodisation » des procédés d'entraînement et systématisation de la planification des combinaisons tactiques dès le premier âge technique de ce sport au tout début du $\mathrm{xx}^{\mathrm{e}}$ siècle.

Cette sociogenèse pose les bases d'une pratique durable aux États-Unis d'Amérique et arrête les contours d'un système technico-moral prêt à être exporté de par le monde, dont la spectacularisation et la marchandisation sont parmi les aspects les plus visibles. Le développement parallèle d'un basket-ball amateur et protégé en milieu scolaire et universitaire ne l'ampute d'ailleurs nullement de sa vocation au divertissement et au spectacle. En outre, il reste dans tous les cas largement marqué de volonté personnelle d'accomplissement, d'esprit de compétition et de voie d'ascension sociale qui en font l'un des symboles de la culture capitaliste américaine.

\section{Les conséquences corporelles d'une sociogenèse}

Cette sociogenèse contribue à la fabrique d'une conception productiviste et industrielle de la performance corporelle. Mécanisation des gestes et des dispositifs tactiques, sélection progressive des athlètes les plus adaptés, spécialisation extrême des compétences et des rôles dans le jeu ont contribué à l'émergence d'une culture corporelle de la productivité reléguant sensations, émotions et subjectivité au rang de l'inutilité. En outre, le basketball se présente comme un vecteur de privation et d'ascétisme. Les valeurs d'effort, d'abnégation, voire de souffrance dans l'entraînement contribuent à une représentation quasi doloriste de son apprentissage ${ }^{13}$. De surcroît, le légalisme imposé via la sacralisation 
de la règle et l'inéluctabilité de la hiérarchie sportive en ont rapidement fait un sport survalorisant un rapport pédagogique hautement directif entre entraîneurs et entraînés. Ainsi le corps docile et soumis, respectueux de l'ordre s'en trouve souvent amputé de sa dimension subversive ou créatrice.

Deux autres aspects originels mériteraient un développement qui ne peut avoir lieu dans ce cadre restreint. L'émergence d'une formule de jeu féminine, quasi concomitante de la version masculine, pourrait être explorée. L'intérêt se situerait dans l'analyse de l'adaptation du jeu - effectif de joueuses supérieur, limitation des zones d'action sur le terrain - répondant aux stéréotypes construits du genre féminin à la fin du XIXe siècle: grâce, fragilité, instabilité mentale et égoïsme. D'autre part, l'étude du basket-ball en tant que potentiel de diffusion d'un «soft power» américain (Nye 1990) s'appuyant sur des pratiques culturelles relayées par le réseau transnational des YMCA achèverait de dépeindre les traits de cette sociogenèse. Ainsi, plus qu'une morale en acte cherchant la formation d'un individu soucieux de son autocontrôle, au-delà d'un terrain d'emprise protestante et de l'espace d'expression d'un esprit capitaliste, le basket-ball serait identifié dès sa création comme un symbole de domination masculine, ainsi qu'un vecteur prosélyte de rayonnement international. De cette matrice originelle, les temps, les espaces et les cultures sauront pourtant s'écarter au profit d'autres usages. En voici maintenant deux exemples emblématiques.

Euro Féminin, 8 juin 2013

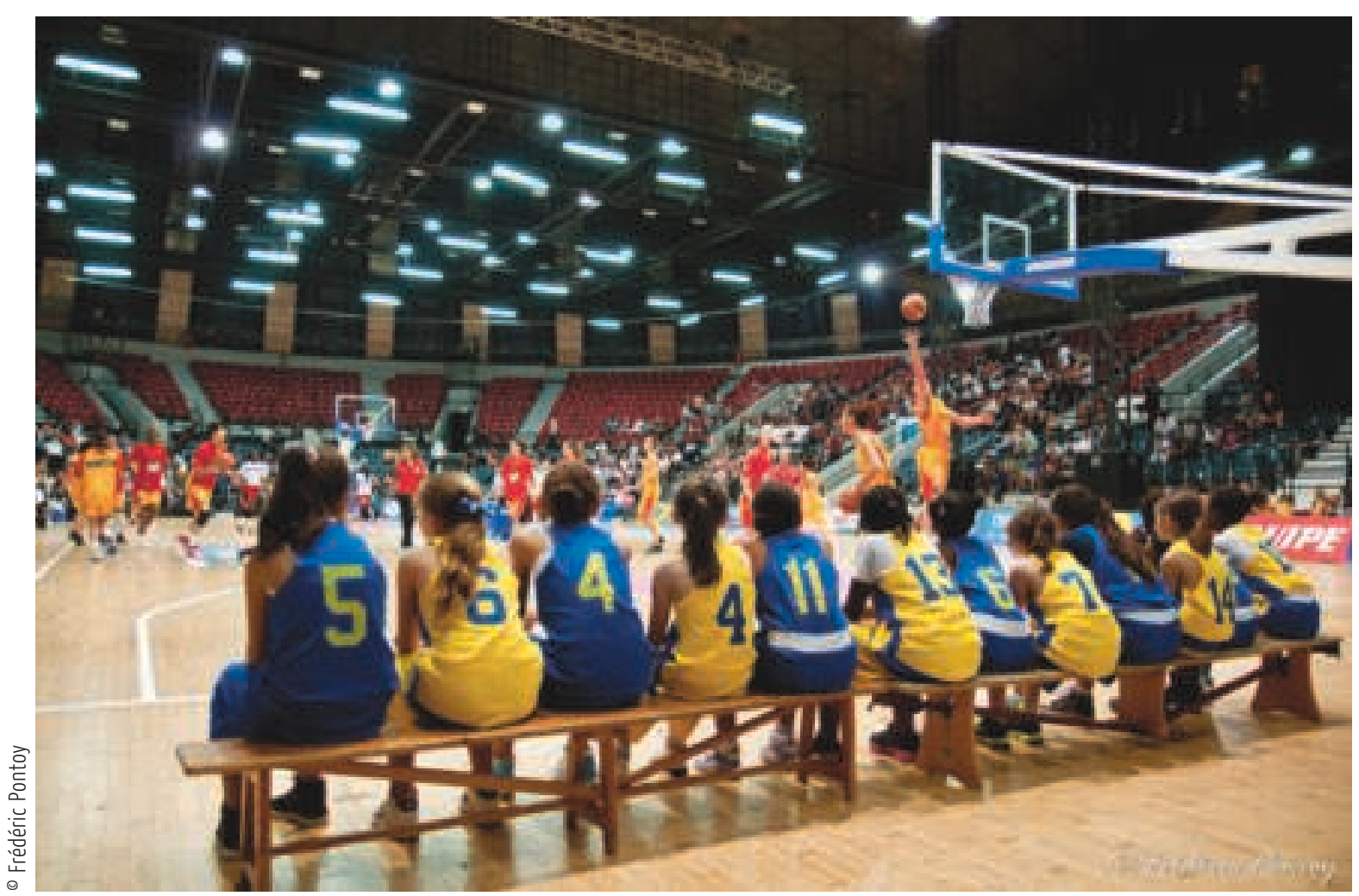




\section{Variabilité socio-historique}

\section{Du basket-ball à la balle au panier : transfert culturel et acclimatation française}

Entre un premier match disputé le 27 décembre 1893 et la création d'une fédération spécifique (FFBB, 1932), s'échelonne en France une période menant le basket-ball d'un statut de curiosité récréative à celui d'un sport en plein devenir. Innovation incongrue pour un pays ayant jeté son dévolu sur les gymnastiques à caractère militaire, patriotique et républicain, il évoque aussi, à la fin du xix e siècle, l'un des attributs culturels d'une puissance dont l'opinion française ignore encore l'expansion. En outre, le contexte anticlérical marquant l'articulation des deux siècles encourage peu la diffusion d'une pratique suspectée de prosélytisme chrétien, tandis que le rôle décisif accordé au corps dans la formation spirituelle selon la muscular christiannity semble «incompris» aux yeux d'un peuple marqué par ses traditions catholiques (Chavinier 2011). Enfin, la logique du basket-ball, composée d'adresse et d'évitements, exprime un rapport au corps très distant de la culture corporelle qui pré-

Règles du jeu de l'UcJG de Paris, 1913


1988, 2011). Il faut finalement attendre les années 1917-1919 et l'influence du corps expéditionnaire américain stationné en France pour qu'un transfert culturel s'amorce (Claverie 2011).

Simultanément se joue un autre glissement: le passage à la sphère d'influence catholique. Il débute avant guerre avec l'accueil un peu méfiant de la Fédération gymnique et sportive des patronages de France (FGSPF) vis-à-vis de ce produit anglo-saxon, qui le propose alors en alternative ludique et informelle au football, pratique compétitive, quasi instituée et performative. Le basketball, émancipé de sa matrice idéologique protestante, contrebalançant l'autonomisation du football et la laïcisation de ses pratiques au début des années 1920, devient dès lors la pratique corporelle catholique par excellence. C'est donc dans un contexte fort différent du creuset de naissance originel que la pratique du basketball va croître en France. Selon quelles modalités corporelles, avec quelles significations et pour quelle acclimatation française?

Le contrôle spirituel de la jeunesse selon une «théologie des corps» (Groeninger 2004) cède alors la place, dans l'entre-deux-guerres, à la concurrence entre réseaux d'influence idéologique et politique. La rivalité mobilise les forces laĩques agissant au sein des amicales, celles du sport catholique, puis après la Deuxième Guerre mondiale, les militants du sport travailliste. Aux yeux de l'institution catholique, le basket-ball symbolise surtout un corps protégé d'autrui qui s'oppose à la violence et la promiscuité corporelle du rugby, par ailleurs relayé dans les petites villes de province par la notabilité laïque (Augustin 1985). Il incarne enfin, par sa présence imposante dans les cours de patronages, un excellent vecteur prosélyte en direction de la jeunesse (Chêne 2003). 
À l'inverse, la sphère d'influence laïque agissant de l'école aux amicales lui donne un autre sens. L'espoir consiste souvent à perfuser auprès des jeunes un esprit républicain et une prise de conscience aiguë de son rôle citoyen. Ainsi, le jeune instituteur et entraîneur de l'équipe du village, héros du film Du Basket et des hommes (Guej 1951), entend, grâce au basket-ball, initier à « une discipline librement consentie au profit d'une équipe, donc d'une société». En définitive, dès sa bascule d'un jeu à un sport en France au lendemain de la Première Guerre mondiale, le basket-ball prend l'allure d'un attracteur puis d'un marqueur idéologique de la jeunesse. Reconstruit à partir d'une identité corporelle originelle, il laisse le loisir à chaque réseau de retravailler à sa convenance cette matrice de base ${ }^{14}$.

Par ailleurs, il représente, des années 1920 à la Seconde Guerre mondiale, un support identitaire national, au travers d'une francisation obstinée. Dès les années 1910 circule déjà dans l'étroit cercle des initiés de la FGSPF le nom de «balle au panier» comme traduction préférée au vocable américain. Se retrouvent aussi, dans les entrefilets de presse, les néologismes de basket-ball ${ }^{15}$ ou plus localement de «basquet » comme pour mieux se démarquer du lointain cousin américain. Le désir de singularisation emprunte aussi la voie des usages et des pratiques. Ainsi, le jeu en plein air, foncièrement étranger au projet de Naismith, est loué en France pour ses vertus hygiéniques; il est également réclamé par les dirigeants de la Commission basket-ball de la Fédération française d'athlétisme à laquelle le basket-ball se rattache encore. La démarcation du jeu américain renvoie jusqu'à l'option tactique d'un tempo endiablé privilégiant les qualités d'endurance des joueurs, source de santé. La double représentation d'un sport américain, autant vicié par ses calculs stratégiques que par les volutes de tabac et les tractations de ses parieurs-spectateurs, s'efface au profit d'une pratique spontanée, saine et aérée. De surcroît, le désir de francisation s'exprime au moyen d'usages techniques et d'une stylisation adaptés à la psychologie du joueur français, plus précisément à son «tempérament » universellement idéalisé. L'annuaire de la FFA pour l'année 1927 présente ainsi ces traits: «finesse, vitesse, clarté et correction [...] élégance et intelligence qui vont si bien avec le Français ${ }^{16}{ }$. Simultanément, la brutalité américaine est vilipendée, de même que la lenteur calculée et le manque d'élégance de ses joueurs sont mis au ban. Dans un réflexe de rejet, il s’agit d'opposer «le charme juvénile et malicieux [...] la grâce bondissante improvisée et fantasque [...] au caractère de sévérité puritaine (celui du jeu Nord américain) à quoi nous nous faisons mal ${ }^{17}$ ».

Plusieurs indices d'affranchissement de la technique américaine au profit d'un style alerte, improvisé et fantaisiste, que l'on nomme alors Ripopo (Claverie 2007), sont perceptibles. Outre sa préférence à être exécutée en extérieur afin de satisfaire la doxa hygiéniste, la balle au panier réclame un code de jeu hexagonal adapté à la corporéité française : l'interdiction du «blocage au corps» du ballon, le chevaleresque «deux contre un » et «l'appréciation plus stricte des fautes personnelles» imposés «par la nervosité et l'impétuosité du caractère des Français ${ }^{18}{ }$. Ainsi le Ripopo français, fait de «brio, détente, vitesse et adresse ${ }^{19}$ » aux «styles libres » reniant toute technique standardisée, s'accorde avec précision à ce système de représentations sociales idéalisées du génie français: «tempérament latin, tout d'improvisation, d'initiative personnelle, de verve, de fougue», mais aussi «vivacité d'esprit du français, [et sa] subtile perspicacité ${ }^{20}$.

Ainsi durant cette vingtaine d'années, tout indique l'affirmation d'un style construit en opposition au modèle américain dont les dirigeants fédéraux contestent le caractère lent et empesé, calculateur et parfois rugueux. Les raisons de ce marquage identitaire tiennent à la récupération catholique du basket-ball, et par là même au désir de s'émanciper de 

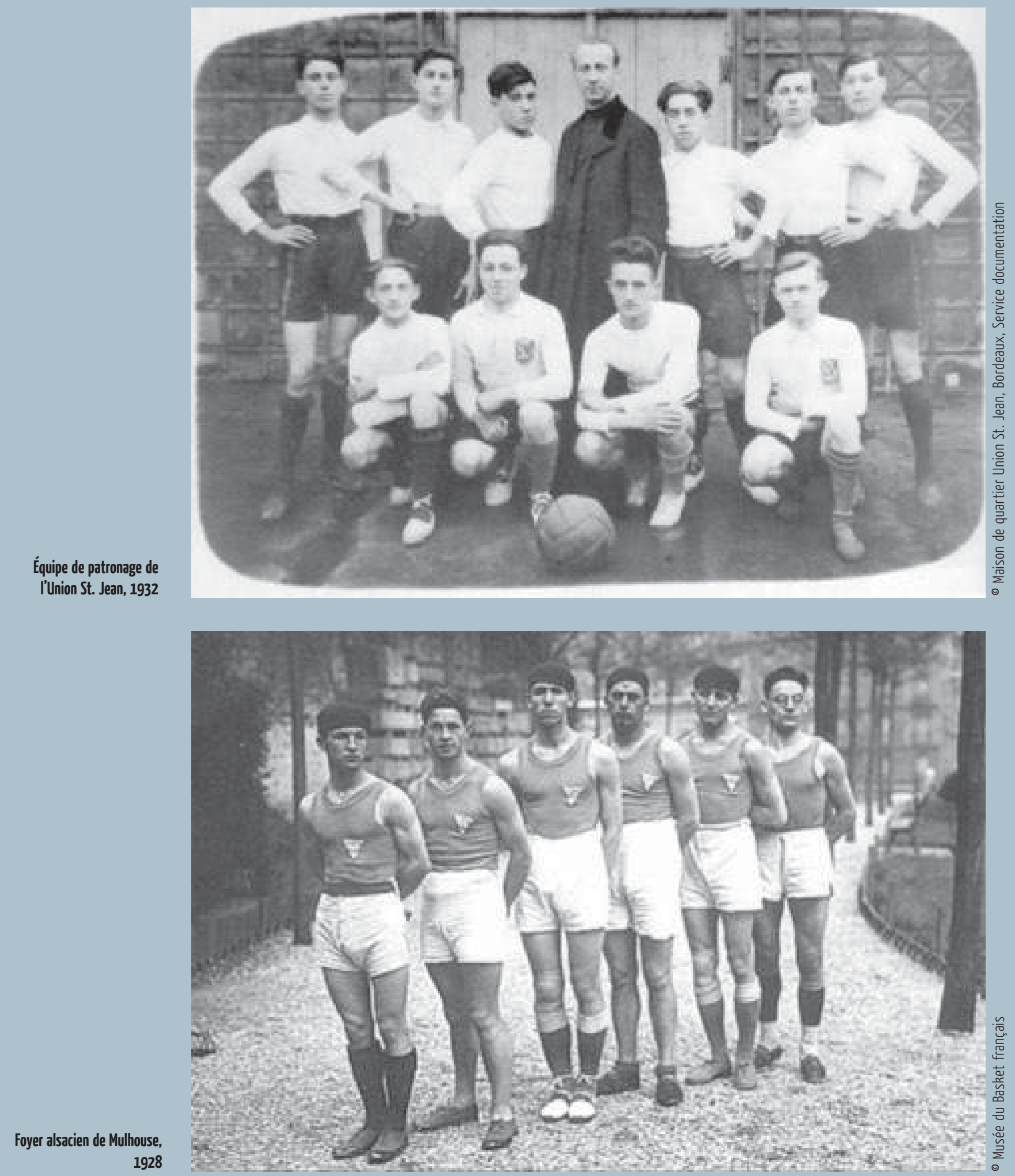
ses racines américano-protestantes. Cette mise en jeu corporelle, réinterprétée selon les codes culturels français ${ }^{21}$, illustre un mécanisme de contre acculturation travaillé par un antiaméricanisme croissant ${ }^{22}$ : l'intérêt et la passion pour ce sport ne pouvant se justifier que dans une singularisation typiquement française de son usage vis-à-vis d'une «nation n’inspirant plus que méfiance et aigreur» (Rioux \& Sirinelli 1999). En outre, cette francisation marquée, expression d'un ethnocentrisme allant crescendo jusqu'à son apogée au cour des années 1930, emprunte au discours pseudo scientifique d'une prétendue psychologie des peuples ${ }^{23}$ pour justifier une manière de jouer. Ainsi, le jeu français garde son caractère hexagonal tout en satisfaisant les stéréotypes les plus communs: « caractère explosif, impulsif et spontané» dont «la facilité est [le] premier don intellectuel».

Au final, l'acclimatation française du basket-ball révèle de multiples singularités. En investissant rapidement les provinces françaises dès l'entre-deux-guerres pour devenir un sport rural villageois empreint de solidarité locale et de fort chauvinisme ${ }^{24}$, il trahit une première marque d'acculturation. Par ailleurs, en devenant l'un des premiers attracteurs de la jeunesse catholique française, il se débarrasse d'une part de sa dimension performative et de sa rationalisation technique poussée, et d'autre part de sa légitimité scolaire et universitaire acquise aux États-Unis d'Amérique. Longtemps ignoré de l'institution scolaire (Claverie 2014), il conserve ainsi durablement le statut de jeu récréatif ignorant un corps efficient. À l'inverse, dépassant les enjeux d'une spiritualité en acte qui l'avaient façonné, il se transforme en marqueur idéologique ou identitaire sous l'influence des divers réseaux de diffusion.

Ainsi, à partir de racines communes, basket-ball français et américain témoignent d'une mise en jeu différente des corps, suggérant qu'un transfert culturel ne peut survenir sans une indispensable acclimatation à la société d'accueil. Apprécions à présent un glissement d'une nature plus temporelle que spatiale.

\section{Basket-ball de rue: sous culture contre-culture sportive?}

Les origines historiques du streetball américain, pratique urbaine de plein air hors cadre institutionnel, mériteraient d'être détaillées dans le cadre d'une étude spécifique ${ }^{25}$. Rappelons brièvement la genèse de sa forme moderne, inséparable du mouvement urbain d'émancipation sociale et politique de la communauté afro-américaine par le sport, parfois qualifié «d'assimilationnisme musculaire» (Ross 2004). Elle s'enracine dans la région new-yorkaise dès 1920, dans l'atmosphère de la Harlem Renaissance et du New Negro. Dans ce contexte, des joueurs africains-américains appartenant à des équipes ségréguées, se produisent et créent au son du jazz un style de jeu vif et bondissant nommé Negro Ball. Ils popularisent ainsi, avec leurs homologues musiciens et danseurs, un nouveau rapport au corps dans l'imaginaire américain : un style noir (Caponi-Tabery 2008). Après-guerre, les basketteurs des ghettos urbains ${ }^{26}$, impriment de plus en plus leur marque au jeu par une empreinte véloce et aérienne, provocatrice et spontanée, qui prend une allure protestataire en pleine période de conquête des droits civiques des noirs américains (Martin-Breteau 2011). Ce basket urbain popularise notamment le geste du slam dunk, symbole de revanche et de destruction d'un ordre social contraint (George 1999). Puis les années 1970 et 1980 consacrent l'institutionnalisation de ce style dont les gestes pénètrent progressivement les milieux académiques du basket-ball, en se défaisant peu à peu de leur marque d'insoumission. Il s'associe au mouvement culturel du hip-hop qui prend naissance au même moment dans le South Bronx, tandis que les grands équipementiers 
sportifs récupèrent le mouvement et convertissent en arguments de vente les marques culturelles de ce passé: style de jeu instinctif, rebelle, aérien, spontané, libre.

Porteur de ce lointain héritage américain, le basket de rue fait son apparition dans les banlieues parisiennes à la fin des années 1980 et s'y développe en parallèle de l'enracinement d'une culture hip-hop (Serina 2004). Cette diffusion favorise l'émergence d'une culture streetball d'abord en marge de la culture sportive classique du basket-ball associatif.

Le renouvellement des pratiques sportives, dans le monde occidental à la fin du xx siècle, a incité plusieurs chercheurs (Loret 1995; Pociello 1995; Chantelat et al. 1996; Adamkiewicz 1998; Coakley 2003; Lebreton 2010) à repenser leurs formes et leurs significations. Dans cet ensemble - pratiques aventureuses, pratiques vertigineuses, pratiques expressives, pratiques d'entretien, pratiques de glisse, pratiques autoréflexives - ont émergé les modes sportifs urbains diversement étudiés pour leur caractère auto-organisé, leur sociabilité réticulaire et connivente ainsi que leur forte stylisation corporelle. Le streetball, désormais installé depuis près de trois décennies sur le sol français, peut-il relever de ces analyses?

Selon les mots d'une étude spécifique déjà ancienne (Vieille-Marchiset 1998), la dimension spectaculaire et ludique des actions y est primordiale, de même que «la sociabilité de proximité» qu'il occasionne. Ces paramètres le rangent donc dans la catégorie des pratiques alternatives urbaines précédemment évoquées. Or d'autres traits témoignent d'une originalité corporelle: sa «rudesse», sa «vigueur» pouvant aller jusqu'à la brutalité des actes sinon des mots ${ }^{27}$; la dimension « intuitive» et « créatrice» de ses gestes; le système de pouvoir qu'il instaure, favorisant une réglementation en «négociation constante», soustrayant à la régulation des actes de jeu toute forme de répression. Ces symptômes d'une pratique spontanée associant des profils d'acteurs très variés, autonome et finalement socialisatrice, sont donc révélateurs d'une forme contre-culture sportive « entre liberté et dissidence». Or ne sont-ils pas aujourd'hui débordés par un développement nouveau?

Les premiers signes d'inflexion tiennent à la fois à une américanisation accentuée ainsi qu'à une intégration plus marquée au mouvement culturel du hip-hop. L'usage systématique de l'idiome américain dépasse le recours au vocabulaire anglo-saxon pour qualifier les «moves» des joueurs fétiches. Il nourrit également les titres des reportages que l'on trouve désormais à foison sur internet ou leurs slogans: «Bring your game, not your name» clament par exemple les organisateurs d'un célèbre tournoi parisien. Un étonnant jargons'échappe aussi de la bouche des pratiquants: «J'ai eu de bonnes vibes, j’ai kiffé [...] j'étais dans le game [...] on était sur le terrain à l'œeil de l'underground [...] ça c'est du real, vous allez kiffer ! ${ }^{28} »$. Langlo-saxon est évidemment le langage du basket-ball. Or il est surtout celui d'une culture urbaine transnationale associant diverses pratiques dont le streetball n'est qu'un des éléments. Ainsi, les diverses évolutions sur les playgrounds ne sauraient s'exonérer de musique rap à haut volume rythmant les gestes sportifs. La présence de ses stars américaines, de celles du beat-boxing, est de plus en plus courante lors du grand tournoi parisien Quai 54. D’autres confrontations (The Pigalle BB Tournement, PXA) mettent en avant l'art graphique ou vidéographique et indiquent, elles aussi, leur volonté de positionner le basket de rue dans une expression culturelle urbaine globale.

Ceci introduit un nouvel élément: l'inclusion de ces manifestations dans une culture du divertissement et du spectacle. Les barrières tombent ainsi entre les espaces classiques de représentation scénique et ceux réservés à l'exercice sportif; les performances, qu'elles soient artistiques ou sportives s'entremêlent lors des tournois organisés. Plus spontanément, les effusions scandées ou dansées répondent aux exploits du terrain. De l'aveu de l'organisateur du tournoi phare parisien, l'entreprise se démarque précisément des 
standards classiques par ces aspects: « un basket un peu moins fédéral et un peu plus entertainment ${ }^{29} »$. En sondant les mentalités, on est d'ailleurs frappé de l'attirance pour la mise en scène de soi qui confine au narcissisme. Les actions de jeu réussies prennent l'allure d'exploits dans le regard de spectateurs en attente de ce show permanent, renforcé par l'omniprésence des supports technologiques de filmage et la promesse d'une large diffusion en ligne: «Quand tu fais le show, le public devient fou ${ }^{30}$ ».

Ce puissant désir de médiatisation va de pair avec la forte stylisation évoquée par les participants. Ainsi, il ne suffit pas de marquer le jeu de l'empreinte de l'efficacité, mais le faire selon une esthétique propre aux membres de cette confrérie. Le style renvoie aux canons d'une certaine élégance décontractée et naturelle, le swag: «Tu ne peux pas venir sur un terrain de street en étant débraillé ou avec une paire de chaussures trouées [...] c'est presque un défilé $e^{31} »$ explique ainsi une participante. Au sein d'une famille aux codes comportementaux très arrêtés, le paraître est essentiel. La personnalisation de son image résulte du port d'accessoires durant le jeu (casquettes, bonnets...) ou de marques corporelles très visibles (coupe de cheveux, tatouages).

L'observation des corps recèle par ailleurs d'autres significations. La décontraction, l'aisance et la fluidité sont érigées en règle constante au détriment de l'effort besogneux ou brutal. Ces qualités ramènent incessamment à une attitude «cool» et «facile» s'inscrivant sans doute en rempart de la dureté du monde du travail que ces adeptes ne connaissent pas encore ou de la précarité économique qui les entoure souvent. Paradoxalement, ils revendiquent aussi les vertus du combat, de la lutte compétitive comme source d'élévation: "Vous voulez jouer, rentrez sur le playground et faites-vous votre place. On ne va pas vous la donner, il faut la prendre ${ }^{32}$. Pour ces jeunes, le terrain de jeu est donc celui de la vie: il révèle les vraies valeurs et permet d'occuper

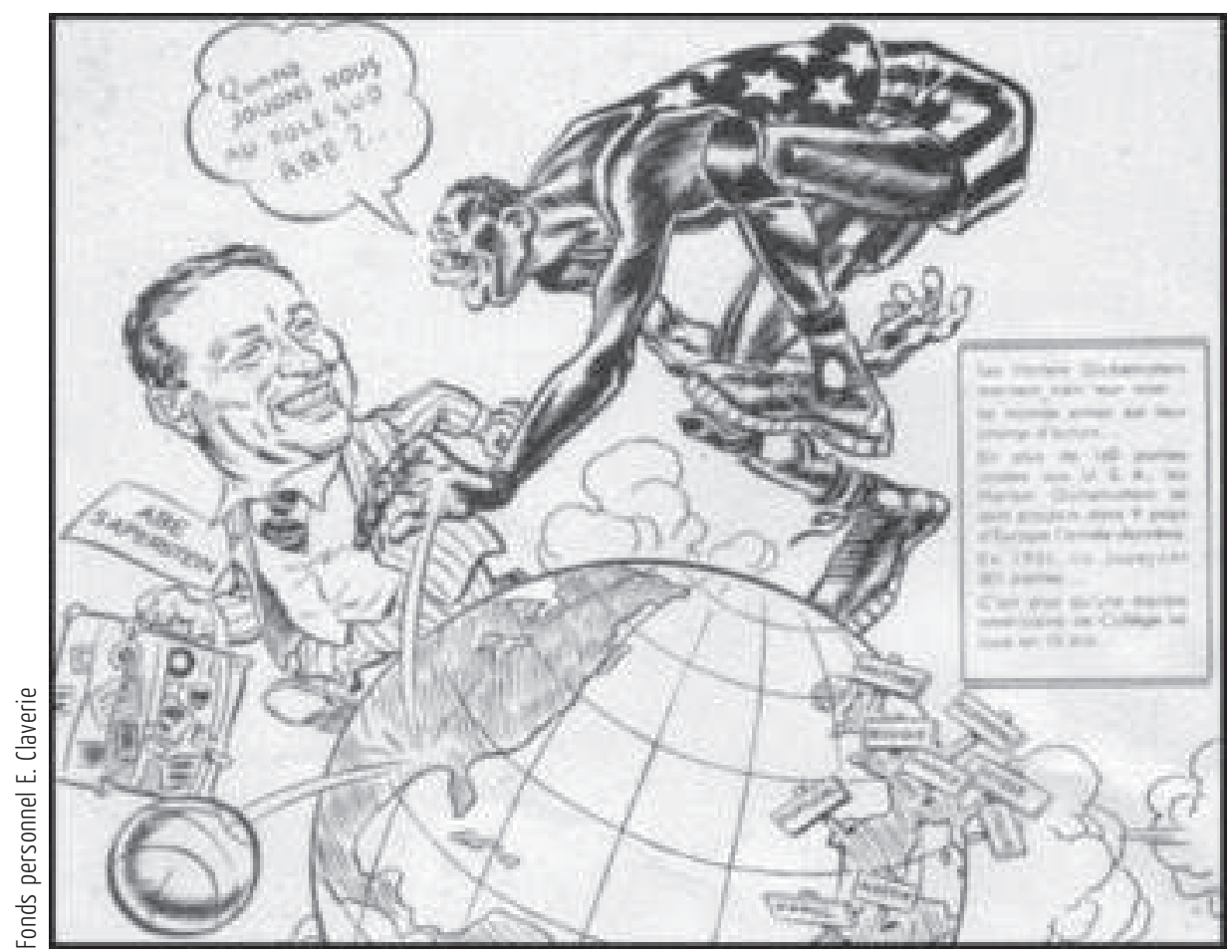

Tournée Européenne Harlem Globetrotters Brochure présentation tournée européenne Harlem Globetrotters 1951. 


\section{Santiago de Cuba, février 2011}

le devant de la scène tant que son expertise l'y autorise ${ }^{33}$. Ils acceptent donc bien volontiers l'idéologie libérale de la compétition comme moteur du succès et d'ascension sociale. Alors les rapports de force tendus entre joueurs fonctionnent fréquemment sur le mode de la provocation et de la domination. Ainsi le dunk, autrefois chargé de sa symbolique émancipatrice, reste le geste technique phare du streetball. Il représente le sommet de la domination sur l'adversaire, "postérisé» (toujours l'image) par un puissant «tomar ${ }^{34} »$ qui le pousse, vaincu en arrière ou au sol. Porteur de la même logique, son pendant défensif, le contre ou «scotch», «cake» ou «bâche», soulève également les vivats de la foule lorsqu'il expulse loin du cercle le ballon: «get back», «not in my house» crient alors les partisans de cet intimidateur. Le même raisonnement peut être tenu à propos du « $\operatorname{cross}^{35}$ », dribble croisé ridiculisant son vis-à-vis sans pourtant conduire nécessairement à la marque. La symbolique dominatrice des gestes se révèle alors plus importante que leur efficacité même.

Ces registres de motricité qui représentent les standards techniques ne sont pourtant pas appris dans le cadre classique des entraînements, mais grâce à l'observation/imitation systématique des stars américaines. Dès lors, la normalisation technique et avec elle le refus de son cadre formel d'apprentissage - le club - laisse place à la stylisation des mouvements. S’opposant à la répétition et à la standardisation, la créativité individuelle l'emporte et devient une ressource de jeu: «le streetball est incomparable car c'est le lieu de la créativité »; « Tout comme un musicien qui joue dans la rue, ces joueurs ont beaucoup d'imagination ${ }^{36}$ ».

Or, deux modalités de streetball semblent désormais se différencier quelque peu.

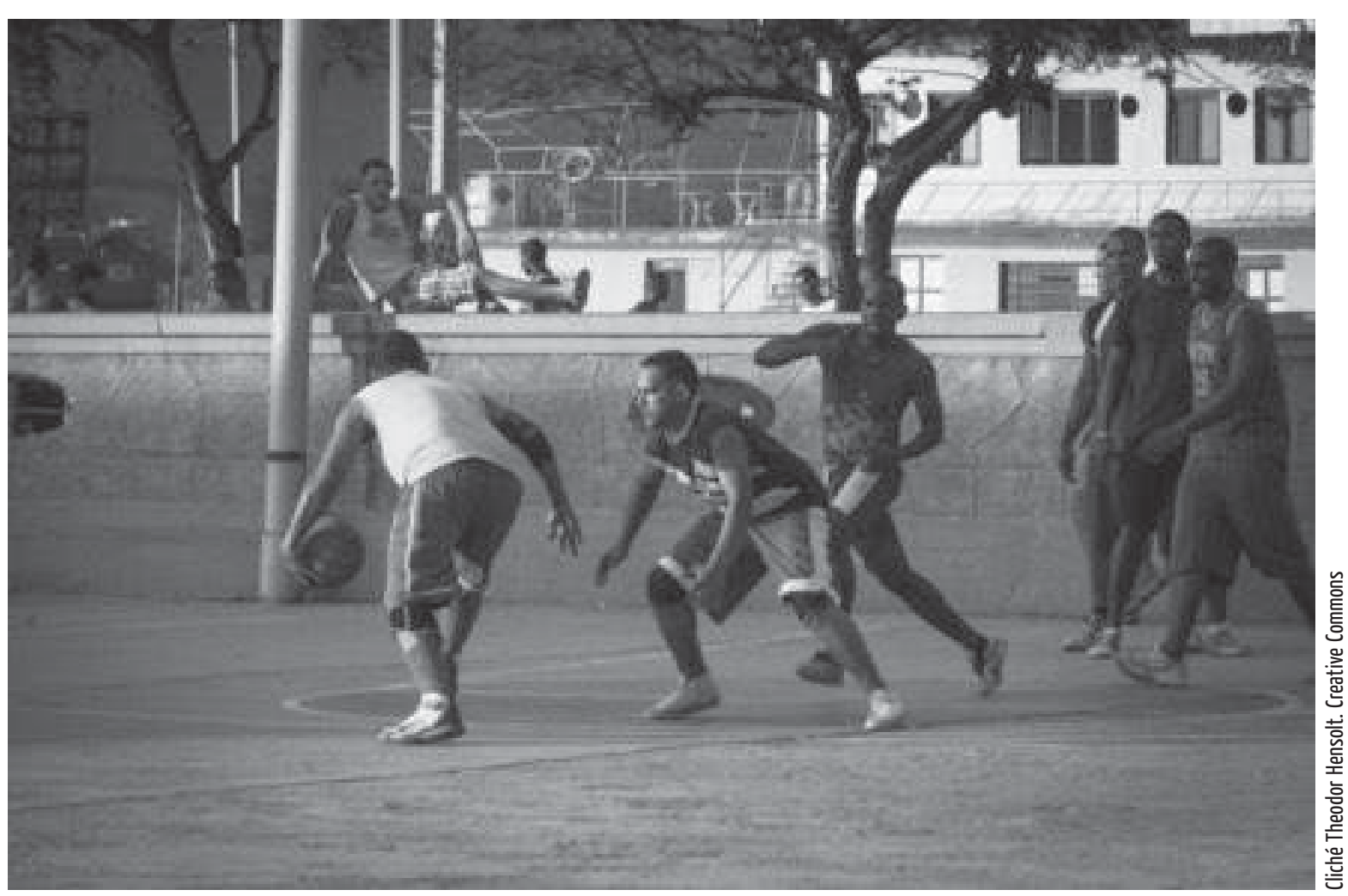


d'années ${ }^{37}$. S'ils associent aux épreuves de basket-ball des manifestations culturelles urbaines, les formes compétitives paraissent se rapprocher des standards fédéraux. Quelques joueurs professionnels y prennent régulièrement part, tandis que les matchs arbitrés s'y font en cinq contre cinq, sous la direction d'un « coach », en s'écartant donc de la formule traditionnelle du streetball américain: jeu à effectif varié pratiqué en autonomie. Mais d'un autre côté, continuent de se développer des formes plus expressives et quasi artistiques de pratiques qui survalorisent les habiletés individuelles, en particulier celle du maniement de ballon dans une virtuosité stupéfiante. Ce type de gestualité qui combine performance motrice, complicité avec un adversaire feignant sa domination

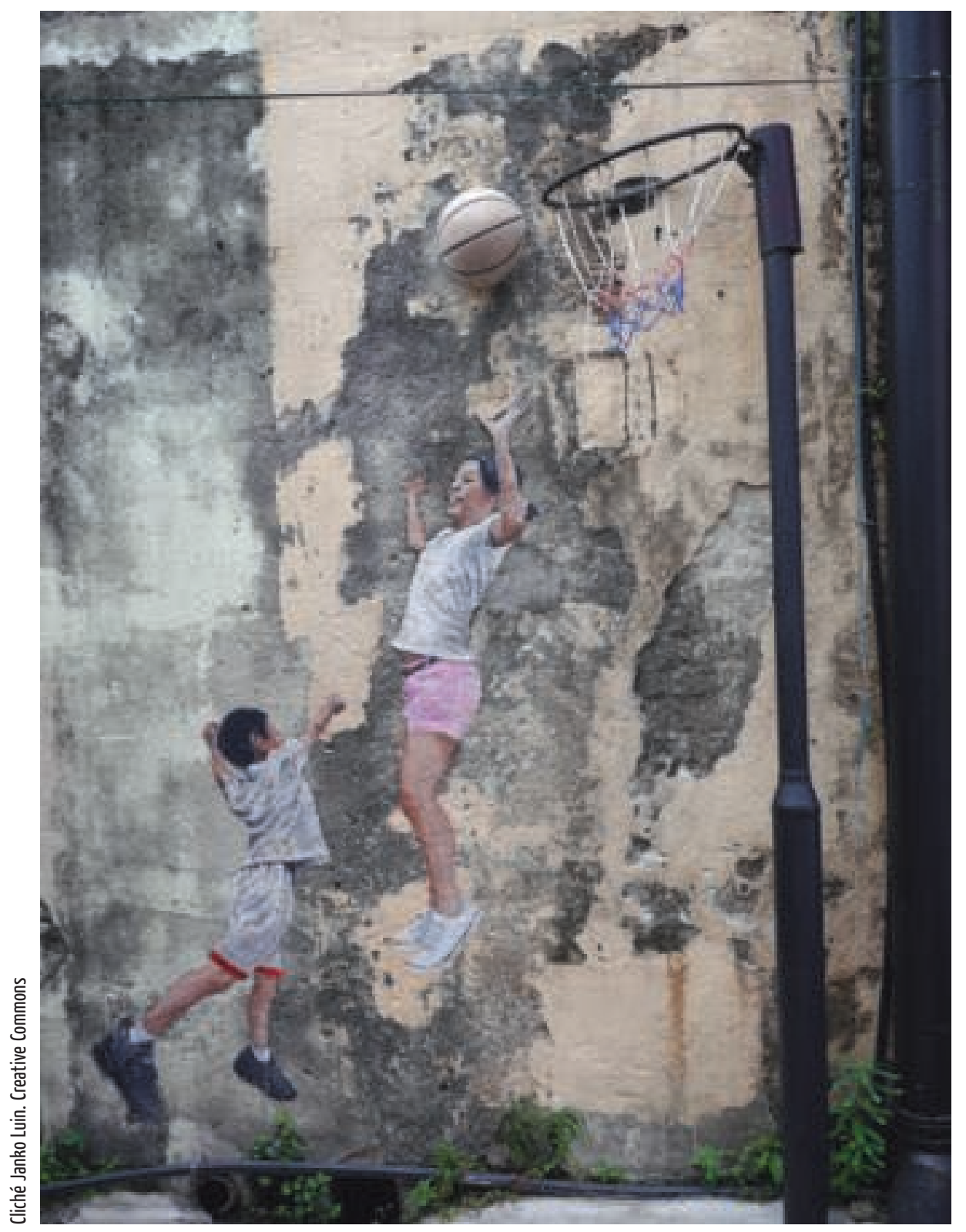

"Sœur et frère jouant au Basket », Goergetown, Penang, Malaisie, décembre 2015 
et spectacle, loin de l'efficience sportive, rappelle les facéties développées par l'équipe des Harlem Globetrotters dès les années 1920 à des fins de divertissement commercial.

Au-delà de ces différences peut-être en cours d'accentuation, nous voyons dans ce jeu du corps qu'est le streetball l'expression contrastée d'un mouvement culturel de la jeunesse urbaine, donnant certes à la concurrence, au défi et à une forme de narcissisme une place centrale. Pourtant, elle signifie également une ouverture sur autrui et un désir de partage observable lors de ces manifestations joyeuses et confraternelles: «Quand la rue ramène ce qu'elle a de meilleur, elle donne ce qu'elle a de meilleur ${ }^{38} \%$. Né au États-Unis d'Amérique d'un mouvement servant la cause de l'émancipation des africains-américains, le streetball incarnait déjà de par ses valeurs une forme de contre-culture sportive au regard des usages professionnels ou universitaires. Parvenu en France, il reste marqué de quelques uns de ces fondements historiques: un style corporel combinant distanciation décontractée et personnalisation gestuelle; une certaine violence des mots et des actes; une attitude d'insoumission et de provocation; et un désir simultané d'appropriation de l'espace urbain. Or, même si la présence noire et métissée y est nettement supérieure à sa représentation nationale, cette forme semble s'être détachée de la fonction contestataire et revendicative originelle pour ne plus représenter que l'expression juvénile d'une ultra modernité urbaine incertaine de son avenir.

\section{$\&$}

Cette étude nous a conduits à appréhender le basket-ball en tant que conduite corporelle signifiante née d'une matrice réglementaire et axiologique lui conférant sa structure. Nous avons également considéré cette pratique comme une forme d'expression issue et procédant d'un mécanisme englobant, celui des dynamiques sociales passées et présentes. En ce sens, le basket-ball comme le sport « constitue bien un construit culturel, évolutif, produit et agent de transformations historiques et sociales: sources d'interrogations et de connaissances incontournables pour l'étude de nos sociétés modernes» (Robène 2004).

En réalité, le jeu de James Naismith, de par sa mission prosélyte, sa diffusion internationale et ses diverses réinterprétations est aussi un bon révélateur des métissages qu’a engendré le $\mathrm{xx}^{e}$ siècle. Il est un témoin «des processus de globalisation, de résistance culturelle ou d'indigénisation créative de pratiques forgées dans d'autres contextes que ceux des sociétés qui les mettent en œuvre» (Bromberger 2004). Il constitue notamment un indicateur des processus de transferts culturels à l'œuvre dans l'espace et dans le temps, et dévoile les capacités d'accueil d'un groupe social ou d'une société susceptible de le modeler, selon son ethos, jusque dans ses usages concrets: «Tantôt ces différences ont modifié l'esprit ou les règles du jeu, tantôt - et plus souvent à l'heure de la mondialisation - elles ont affecté le style des pratiques» (Bromberger 1995).

En définitive, à l'heure de fêter son cent vingt-troisième anniversaire, le basketball contemporain est assez fidèle à ses origines: des espaces de jeu assez proches des standards fixés à l'origine (en particulier les fameux dix pieds inchangés de hauteur du cercle), des règles cardinales sanctuarisées (déplacements et contacts) et des principes ludo-moteurs conservés ${ }^{39}$. La structure des premiers âges, autant bâtie autour d'un noyau réglementaire que d'un corps axiologique, lui confère effectivement une stabilité identitaire. Pourtant plusieurs adaptations singulières traduisent aussi sa forte porosité aux 
milieux socioculturels d'accueil, laissant finalement penser que les propriétés formelles de ce sport sont loin d'être les seules à en déterminer les règles de diffusion. En pérénisant ses valeurs tout en autorisant la plasticité de ses formes motrices, le basket-ball illustre bien la relativité de la modernité des sports «ayant pour caractéristique essentielle de préserver des invariants tout en s'adaptant aux conjonctures» (Arnaud et al. 2008: 21).

\section{NOTES}

1. Basket-ball, 15/11/1934: 2 .

2. Tour à tour, joueur international, entraîneur, président des fédérations françaises et internationales des années 1930 à 1980 .

3. Entendue selon A. Burguière en 1986 comme « un effort pour relier l'évolution d'une institution, d'un type de consommation ou d'une technique à sa résonance sociale et aux comportements qu'elle a engendrés».

4. Nous ne pouvons ici qu'évoquer quelques productions s'attachant à décoder les significations des gestes sportifs (Bruant 1992; Pociello 1996; Darbon 2002, 2008, 2014; Wahl 2002; Bromberger 1995, 1998; Lebreton 2010; Raveneau 2006; Fournier \& Raveneau 2008, 2010)

5. Ce fils d'immigrés écossais, natif du Canada, est passé à la postérité grâce à l'« invention du basket-ball ». Issu d'une famille pauvre, rapidement orphelin, il s'adonne avec passion à de nombreuses pratiques ludiques et sportives. Ses études religieuses à Montréal en feront plus tardivement un ministre presbytérien. C'est également dans cette ville qu'il entre en contact avec le mouvement YMCA qui le convainc de l'utilité des exercices du corps dans la formation globale de l'individu. Embauché comme instructeur physique dans la YMCA International Training School de Springfield en 1890, il y développe le jeu de la balle au panier. Également diplômé de médecine, il poursuivra durablement sa carrière de directeur de l'Éducation physique à l'Université de Kansas.

6. Pour P. Parlebas, «La logique interne des jeux sportifs se manifeste fondamentalement dans les prescriptions du code de jeu qui induisent des comportements corporels précis»; «La logique interne d'une pratique motrice peut être réinterprétée de l'extérieur, par une logique externe qui lui attribue des significations symboliques nouvelles ou insolites».

7. Programme de la tournée mondiale des Harlem Globetrotters, 1951.

8. «Basketball Popular», New York Times, 23/12/1902.Les règles du non contact entre protagonistes bâtie autour de la notion de «faute personnelle», de la marque par visée précise sans possibilité défensive d'action dans la phase descendante du ballon, et du contrôle des déplacements sanctionnés par le «marcher » constituent toujours la trame essentielle du code de jeu actuel.

9. Les règles du non contact entre protagonistes bâtie autour de la notion de «faute personnelle», de la marque par visée précise sans possibilité défensive d'action dans la phase descendante du ballon, et du contrôle des déplacements sanctionnés par le «marcher » constituent toujours la trame essentielle du code de jeu actuel.

10. Le mouvement religieux YMCA a été fondé par George Williams en 1844, à Londres, pour venir en aide aux jeunes travailleurs pendant la révolution industrielle. Il comprend plusieurs membres issus de la mouvance évangélique. Très rapidement, il déborde le domaine spirituel pour améliorer les conditions sociales et culturelles de vie des populations ouvrières urbaines. Il atteint le continent américain dès le début de la décennie 1850.

11. Charles Kingsley (1819-1875), cité par Allen Guttmann. On trouve chez lui, ainsi que chez Thomas Hughes (1822-1896) autre écrivain anglais de l'époque victorienne, les premières traces du concept de muscular christianity, notamment dans l'histoire d'un élève de Thomas Arnold à Rugby.

12. «Au travers de la dévotion religieuse au sein des YMCA, un individu pouvait se convertir en un gentleman chrétien, sachant faire preuve d'abstinence sexuelle (en particulier masturbatoire), d'autocontrôle et de résistance au sentimentalisme et à la douleur. »

13. Cette vertu morale attribuée à la souffrance dans l'apprentissage, indispensable à l'accomplissement personnel, est parfaitement explicite dans le documentaire de S. James: Hoop Dreams (1994).

14. Quelques exemples, plus rares, de développement dans un cadre industriel paternaliste, ont également été mis à jour. Pour exemple: Favero, J.-P. 2003 «Le basket à Auboué: du paternalisme à l'autonomisation d'une pratique sportive. » 
15. «Le baskett-ball », Les Jeunes, 18/10/1913.

16. Fédération française d'athlétisme, Annuaire de l'année 1927: 52 .

17. Berger M., Basket-ball no 68, 5/11/1936: 4

18. Commission basket-ball de la FFA, Fédération française d'athlétisme, Annuaire, 1921.

19. Berger M., Basket-ball no 68, 5/11/1936: 4 .

20. Fédération française d'athlétisme, Annuaire de l'année 1927: 52

21. Ce processus d'acclimatation d'un sport étranger aux normes et valeurs françaises n'est pas bien éloigné de celui identifié par Philip Dine qui constate la réappropriation française de la masculinité anglo-saxonne via le rugby.

22. R. Aron et A Dandieu publient un ouvrage retentissant en 1931: Le cancer américain.

23. Psychologie du peuple français d'A. Fouillée en est le meilleur exemple.

24. Parfaitement visibles dans le film À propos de basketball de Claude Cariven en 1948.

25. À la fin des années 1920, on recense 10000 playgrounds dans les villes américaines. New York Times, 14 juillet 1929

26. Holcombe Rucker en 1947 crée le tournoi de rue longtemps resté le plus célèbre à Harlem ainsi que la Rucker's League.

27. Le trash-talking, littéralement «parler ordurier», fait partie intégrante du jeu professionnel et surtout du streetball américain. Il consiste en de discrètes provocations verbales et insultes destinées à déstabiliser l'adversaire.
28. Témoignage joueur, Tournoi Quai 54, Paris, 2012.

29. Témoignage Hammadoun Sidibé organisateur, Tournoi Quai 54, Paris, 2012.

30. Témoignage joueur, Tournoi Quai 54, Paris, 2012.

31. Témoignage joueuse, Tournoi Quai 54, Paris, 2012.

32. Témoignage Evan Fournier, joueur professionnel, 2012.

33. Dans sa version la plus commune, d'inspiration libérale américaine, le vainqueur occupe le playground jusqu'à sa défaite.

34. Un marteau en verlan, pour parler du dunk comme d'un coup puissant et violent.

35. Cross over dribble ou dribble croisé, dont l'invention serait redevable à RPW Kirkland, célèbre joueur de streetball newyorkais des années 1970.

36. Témoignage de Sacha Giffa, joueur professionnel, 2011.

37. Le tournoi parisien Quai 54, du nom de la localisation de son playground d'origine, 54 Quai Michelet, se présente comme le plus grand tournoi de streetball du monde et existe depuis 2003. Il attire jusqu'à 6000 spectateurs et associe performances hip-hop, concours de un contre un, de dunk et son épreuve phare, un tournoi collectif.

38. Témoignage joueur, Tournoi Quai 54, Paris, 2012.

39. Les premiers croisements offensifs de joueurs destinés à gêner leurs adversaires nommés « ciseaux», même en devenant écrans plus rugueux, ont par exemple peu changé en un siècle.

\section{RÉFÉRENCES}

Adamkiewicz, E. 1998 «Les performances sportives de rue», Annales de la recherche urbaine 79: 50-57.

Andrieu, G. 1988 L'Homme et la force. Paris: Actio.

Arnaud, P., Attali, M. \& J. Saint-Martin dir. 2008 Le sport en France. Une approche politique, économique et sociale. Paris: La documentation française.

Aron, R. \& A. Dandieu 1931 Le cancer américain. Paris: Rieder.

Augustin, J.-P. 1985 Histoire sociale des pratiques sportives. Paris: INSEP.

Bromberger, C. 1995 «De quoi parlent les sports?», Terrain 25: 5-12.

Bromberger, C. 2004 «Les pratiques et les spectacles sportifs au miroir de l'ethnologie. » in Société de sociologie du sport en langue française dir. Dispositions et pratiques sportives. Paris: L'Harmattan.

Burguière, A. 1986 Dictionnaire des sciences historiques. Paris: PUF.

Busnel, R. 1955 «Le basket dans le monde.» in Le basket-ball, Encyclopédie des sports modernes, Tome 2. Genève: Kister et Schmid.

Caponi-Tabery, G. 2008 Jump for Joy: Jazz, Basketball and Black Culture in 1930's America. Amherst: University of Massachusetts Press. 
Chantelat, P., Fodimby, M. \& J. Camy 1996 Sports dans la cité, anthropologie de la jeunesse sportive. Paris: L'Harmattan.

Chavinier, S. 2011 «Histoire d'un échec, l'introduction du basket-ball en France (1893-1917)», Science et motricité 72: 40-46.

Chêne, C. 2003 «Les enfants qui savent le mieux jouer sont ceux qui savent le mieux prier. Basket et autres activités dans les patronages catholiques à Paris au xx siècle» in Archambault, F., Artiaga, L. \& P.-Y. Frey dir. L'aventure des "grands" hommes. Limoges: Pulim.

Claverie, E. 2007 «Le Ripopo ou la naissance d'un style français» in Archambault, F., Artiaga, L. \& G. Bosc Double jeu: histoire du basket-ball entre France et Amériques. Paris: Vuibert: 155-163.

Claverie, E. 2011 «Le basket-ball français: styles et techniques d'élite dans le miroir américain. Transfert, acclimatation et résistances (1919-1978)», Stadion 37: 83-107.

Claverie, E. 2014 «Basket-ball scolaire ou scolarisation du basket-ball: histoire d'une présence récente» in Attali, M. \& J. Saint-Martin dir. Contribution de l'épistémologie des APS à la définition de savoirs corporels en EPS: XIXe-XXe siècles. Rennes: Congrès ACAPS.

Coakley, J. 2003 [1978] Sport in Society. McGraw-Hill Education.

Darbon, S. 2002 «Pour une anthropologie des pratiques sportives. Propriétés formelles et rapport au corps dans le rugby à Xv », Techniques\&Culture 39.

Darbon, S. 2008 Diffusion des sports et impérialisme anglo-saxon. Paris: Maison des Sciences de l'homme.

Darbon, S. 2008 «Baseball, immaculée conception et nostalgie pastorale», Terrain 51: 131-147.

Darbon, S. 2010 «Les Pratiques sportives au filtre de l'anthropologie», Revue pour l'Histoire du CNRS 26: 24-29.

Darbon, S. 2011 «Introduction. La diffusion des sports: confrontations disciplinaires et enjeux méthodologiques», Ethnologie française 41.

Darbon, S. 2014 Les fondements du système sportif. Essai d'anthropologie historique, Paris: L'Harmattan.

Dine, P. 2002 «Du collégien à l'homme (aller-retour). Rugby et masculinité en Grande-Bretagne et en France », Le Mouvement Social 198: 75-90.

Favero, J.-P. 2003 «Le basket à Auboué: du paternalisme à l'autonomisation d'une pratique sportive» in Archambault, F., Artiaga, L. \& P.-Y. Frey dir. L'aventure des «grands» hommes. Limoges: Pulim: 141-160.

Fournier, L.-S. \& G. Raveneau 2008 «Anthropologie des usages sociaux et culturels du corps», Journal des anthropologues 112-113: 9-22.

Fournier, L.-S. \& G. Raveneau 2010 «Anthropologie de la globalisation et cultures sportives», Journal des anthropologues 120-121: 39-63.

George, N. 1999 Elevating the Game: Black Men and Basketball. Lincoln: University of Nebraska Press.

Groeninger, F. 2004 Sport, religion et nation. Paris: L'Harmattan.

Gulick, L. H. 1889 Our New Gymnastics.

Guttmann, A. 1978 From ritual to record. The nature of modern sports. New York: Columbia Press University.

Guttmann, A. 1988 A Whole New Ball Game. Chapel Hill: The University of North Carolina Press.

Hurtebize, C. 1990 « Géopolitique de la genèse, de la diffusion et des interactions culturelles dans la culture corporelle et le sport. » in B. Erais dir. Géopolitique du sport. Besançon: Université Franche Comté: 87114 .

Jousse, M. 1974 L'Anthropologie du geste. Paris: Gallimard.

Lebreton, F. 2010 Cultures urbaines et sportives «alternatives». Paris: LHarmattan.

Loret, A. 1995 Génération Glisse. Paris: Autrement.

Martin-Breteau, N. 2011 «Un "sport noir". Le basket-ball et la communauté africaine-américaine», Transatlantica 2/2011. [En ligne] transatlantica.revues.org/5469.

Miller, P. B. 2004 «Muscular Assimilationism: Sport and the Paradoxes of Racial Reform.» in Ross, C. K. dir. Race and Sport: the Struggle for Equality On and Off the Field. Jackson: Univesity Press of Mississipi: 146-182.

Naismith J. 1996 [1941] Basketball, Its Origin and Development. Lincoln: University of Nebraska Press.

Nye, J. 1990 Bound to lead. New York: Basic books. 
Overman, S. J. 2011 The Protestant Ethic and the Spirit of Sport. How Calvinism and Capitalism Shaped America's Games. Macon Georgia: Mercer University Press.

Parker, A. \& N.J. Watson 2014 «Sport and Religion: Culture, History and Ideology », Movement and sport sciences 86, 71-79.

Parlebas, P. 1981 Contribution à un lexique commenté en science de l'action motrice. Paris: Insep.

Plas P. 2003 «Le basket et les patronages à Limoges.» in Archambault, F., Artiaga, L. \& P.-Y. Frey dir. L'Aventure des "grands" hommes. Limoges: Pulim.

Pociello, C. 1995 Les cultures sportives: pratiques, représentations et mythes sportifs. Paris: PUF.

Putney, C. 2001 Muscular Christianity. Cambridge: Harvard University Press.

Raveneau, G. 2006 «Prises de risque sportives: représentations et constructions sociales », Ethnologie française 36: 581-590.

Riess, S. A. 1991 City Games, The Evolution of American Urban Society and the Rise of Sport. Chicago : University of Illinois.

Rioux, J.-P. \& J.-F. Sirinelli 1999 La France d’un siècle à l'autre, 1914-2000, Tome 2. Paris: Hachette.

Robène, L. 2004 «Les cultures sportives et artistiques, objet d'histoire, objet de savoir.» in Loquet, M. \& Y. Léziart dir. Cultures sportives et artistiques. Rennes: PUR: 26-38.

Robène, L. \& Y. Léziart 2006 L'Homme en mouvement. Histoire et anthropologie des techniques sportives. Paris: Chiron.

Ross, C. K. 2004 Race and sport. The struggle for equality on and off the field. Jackson: The University Press of Mississippi.

Schmitt, J.-C. 1990 La raison des gestes dans l'Occident médiéval. Paris: Gallimard.

Schmitt, J.-C. 2008 «Anthropologie historique», Bulletin du centre d'études médiévales d'Auxerre, BUCEMA, Hors-série n 2, [En ligne] cem.revues.org/8862.

Serina, F. 2004 Histoire de l'acclimatation et de l'enracinement de la culture hip-hop dans la région parisienne, 1963-1986, Mémoire d'histoire contemporaine, P. Ory et F. Georgi dir., Université Paris I.

Singaravelou P. \& J. Sorez 2000, L'empire des sports. Une histoire de la mondialisation culturelle, Paris: Belin.

Vieille-Marchiset, G. 1998 «Culture et sociabilité sportive des basketteurs de rue: entre liberté et dissidence.» in Vivier, C. \& J.-F. Loudcher dir. Le sport dans la ville. Paris: L'Harmattan.

Vigarello, G. 1988 Techniques d'hier et d'aujourd'hui. Une histoire culturelle du sport. Paris: Revue EPS.

Vigarello, G. \& R. Holt 2011 «Le corps travaillé» in A. Corbin, J.-J. Courtine \& G. Vigarello dir. Histoire du corps, Tome 2. Paris: Seuil.

Weber, M. 1964 [1904] L'éthique protestante et l'esprit du capitalisme. Paris: Plon.

\section{Filmographie}

Cariven C. 1948 À Propos de basket-ball. Fonds personnel. Production Premiers Plans.

Garcia, B. \& K. Coulieau 2012 Doin't in the park. USA: Goldcrest Films.

Gardner, D. 1997 Soul in the hole. USA: Melissa Neidich.

Guez, R. 1955 Du Basket et des hommes. Fonds personnel. Production Roger Deplanche, France Activités.

James, S. 1994 Hoop Dreams. USA: Kartemquin Films.

Shelton, R. 1992 White Men Can't Jump, USA.

\section{POUR CITER CET ARTICLE}

Claverie, E. 2017 «Significations du basket-ball. Entre constantes corporelles et variabilité socio-historique», in G. Bartholeyns \& F. Joulian, Le corps instrument, Techniques\&Culture 62: 208-229. 


\section{RÉSUMÉ}

Significations du basket-ball. Entre constantes corporelles et variabilité socio-historique. Cette contribution se penche sur les techniques corporelles du basket-ball, pratique sportive anglo-saxonne apparue à la fin du XIX ${ }^{\mathrm{e}}$ siècle. Né dans un contexte éducatif, ce jeu devenu sport, traverse plus d'un siècle en maintenant une bonne part de ses formes originelles. Pourtant ses gestes n'en prennent pas moins des significations variables lorsqu'ils sont plongés dans des environnements sociaux différents, ou lorsqu'ils sont véhiculés dans d'autres espaces géographiques et culturels. Le projet emprunte à l'anthropologie historique des sports et s'inscrit dans la veine de productions récentes (Robène \& Léziart 2006; Darbon 2008, 2014). Il désire d'une part mettre au jour les rationalités corporelles de ce sport, et par voie de conséquence, en comprendre leurs sens. Aussi puise-t-il aux sources historiques de l'œuvre ludique du ministre presbytérien James Naismith afin d'en comprendre sa genèse, tout autant tributaire d'une matrice motrice et réglementaire que d'un contexte idéologico-religieux. D'autre part, l'article explore la variabilité sociohistorique de cette création ludique. Deux exemples d'acclimatation à de nouveaux univers socioculturels sont exposés. Acclimatation à la société française de l'Entre-deux-guerres d'abord, qui, persuadée de le façonner à ses normes, incorpore pourtant bon nombre des fondements axiologiques américains. Acclimatation ensuite aux cultures urbaines des sociétés post-industrielles qui lui confèrent une dimension transnationale et transgressive vis-à-vis de l'académisme sportif. Ces exemples tendent à nuancer l'hypothèse de l'universalité du noyau corporel des origines et à valider celle de l'extrême plasticité des gestes sportifs et de leur signification au regard du contexte environnant.

\section{ABSTRACT}

What does basketball mean? Halfway between physical constants and socio-historical variants. The present contribution studies basket-ball physical techniques, as they occurred among Anglo-Saxon sportive practices at the end of the $19^{\text {th }}$ century. Created for educational purposes, this game became a sport while keeping most of its original features through more than a century. However body-movements donıt have the same meanings, depending of their social environment of performance or when played in other contexts, either geographical or cultural. This project has its roots in the historical anthropology of sports and at the same time is in the vein of recent writings by Robène \& Léziart in 2006, and Darbon in 2008 and 2014. On one hand it plans to reveal how this sport relies upon physical rationalities and, as a consequence, to study their meaning. Therefore, it draws deep into the origins of Presbyterian minister James Naismith>s recreational objectives in order to understand its breeding ground which depended on a matrix both in motricity and regulations, as well as ideological and religious beliefs. On the other hand, in this article, this recreational invention is explored in its sociohistorical variants. Two cases of sociocultural acclimatization are dealt with. The first one during French inter-war period, when French society was convinced of having shaped it according to its own regulations, yet did introduce quite a lot of American axiological principles. The second case of acclimatization comes from postindustrial urban cultures which loaded basket-ball with a transnational and transgressive dimension as compared to sports academism. Both examples tend to qualify the current hypothesis about physical roots being universal and to comfort the extreme plasticity of physical movements in sports and their meaning as regards their surrounding context.

\section{MOTS CLÉS}

Basket-ball, techniques, propriétés formelles, règles, cultures sportives

\section{KEYWORDS}

Basketball, techniques, formal properties, rules, sports cultures 